\title{
ESTIMATION OF EXTREME LOAD EFFECTS ON LONG-SPAN BRIDGES USING TRAFFIC IMAGE DATA
}

\author{
ELENA ALEXANDRA MICU ${ }^{1 *}$, EUGENE JOHN OBRIEN1, \\ ABDOLLAH MALEKJAFARIAN ${ }^{1}$, MICHAEL QUILLIGAN ${ }^{1,2}$ \\ ${ }^{1}$ School of Civil Engineering, University College Dublin, Dublin, Ireland \\ ${ }^{2}$ School of Engineering, University of Limerick, Limerick, Ireland
}

2018/13(4)

Received 29 January 2018; accepted 20 October 2018

\begin{abstract}
This paper proposes an algorithm for the estimation of extreme intensity of traffic load on long-span bridges. Most Weigh-in-Motion technologies do not operate in congested conditions which are the governing cases for these bridges. In the absence of Weigh-in-Motion data on the bridge itself, a correlation between vehicle weights and their lengths is established here using a (freeflowing) Weigh-in-Motion database. Photographic images of congested traffic are modelled here for three bridges using weights estimated from lengths and one year of Weigh-in-Motion data. The actual weights are taken from the Weigh-inMotion data, and the results are compared to test the method. The gaps between vehicles are firstly set to a constant value and later to Beta-distributed values according to vehicle type. The intensity of traffic load for all pictures is calculated and compared to the loads obtained from the recorded weights. A return period of 75-year is chosen to evaluate the extreme values of intensity. The probability that intensity of load is being exceeded is obtained using normal probability paper for both recorded and simulated weights. This study demonstrates the feasibility of the proposed concept of using lengths to estimate the extreme traffic load events with acceptable accuracy.
\end{abstract}

Keywords: bridge, congestion, long-span, traffic load, vehicle length, Weigh-inMotion (WIM).

\footnotetext{
* Corresponding author. E-mail: alexandra.micu@ucdconnect.ie 


\section{Introduction}

The safety of a bridge is accurately assessed when the traffic load and the capacity to carry that load are established. While the capacity of bridge structures has been extensively studied (Attard \& Stewart, 1998; Darmawan \& Stewart, 2007; Pines \& Aktan, 2002; Stewart, 2001; Stewart \& Val, 1999), there are far fewer studies about bridge traffic load (Caprani, 2010; Carey, OBrien, Malekjafarian, Lydon, \& Taylor, 2017; Paeglitis \& Freimanis, 2016). When the probability is low that the load effects (e.g. bending moments) caused by traffic load are less than the resistance, then the safety of the bridge is ensured.

Congested traffic conditions govern for long-span bridges (Getachew, 2003; Hwang, Lee, \& Kim, 2012; Lutomirska, 2009; Nowak, Lutomirska, \& Sheikh Ibrahim, 2010; Sedlacek, Merzenich, Paschen, Bruls, Sanpaolesi, Croce, ... \& Hanswille, 2008). Such heavy traffic situations are defined by a higher number of trucks moving at the close spacing on the bridge (Al-Kaisy, Hall, \& Reisman, 2002). For these situations, estimating the traffic load is a challenge due to a lack of information about the gaps between vehicles, their weights and the car/truck mix. Weigh-in-Motion (WIM) is the most common method used to collect such traffic data (Moses, 1979). However, the accuracy of WIM systems is only proven for free-flowing traffic conditions (Klein, Mills, \& Gibson, 2006). This means that most of these technologies do not work in stop-and-go conditions. Therefore, WIM data collected in congested traffic conditions are unreliable. As cars tend to change lanes when traffic becomes congested, the car/truck mix recorded during free-flowing conditions is no longer valid for a congested state. The result is a lack of congested traffic data for weights, inter-vehicle gaps and car/truck mix.

In recent years, a number of studies have investigated types of congestion (Caprani, OBrien, \& Lipari, 2016; Krauß, 1998) as well as driver behaviour under different traffic conditions (Aghabayk, Sarvi, \& Young, 2012; Al-Kaisy, Jung, \& Rakha, 2005; Ferrari, 1989; Sarvi, 2013; Yoo \& Green, 2009). Other studies have been published on traffic load for long-span bridges (Bailey, 1996; Bruls, Croce, De Falena, \& Sedlacek, 1996; Buckland, 1991; Buckland, McBryde, Navin, \& Zidek, 1978; Ditlevsen, 1994; Hayrapetova, O'Connor, \& OBrien, 2012; OBrien, Hayrapetova, \& Walsh, 2012). Treiber, Hennecke, \& Helbing (2000) propose microsimulation for the modelling of congested traffic. They investigate a mix of car and truck traffic and propose an explanation for the observed wide scattering of congested traffic data. However, microsimulation is computationally intensive, probably excessively so 
for direct simulation of traffic load in long-span bridges (Al-Kaisy, Jung, \& Rakha, 2005; Caprani, 2010; Caprani \& OBrien, 2008; Enright, Carey, \& Caprani, 2013; OBrien, Lipari, \& Caprani, 2015). Caprani (2012) uses microsimulation to calibrate a congested traffic load model. Enright, Carey, \& Caprani (2013) use microsimulation to evaluate the Eurocode load model for American long-span bridges. So far, however, WIM data from free-flowing traffic has been used in most studies, with intervehicle gaps and a car/truck mix, which is not valid for congested conditions. This means that the assumptions made about gaps and car/truck mix have not been validated using real data from congested traffic. Some researchers suggest the use of constant values for the gaps (axle to axle) between vehicles (Getachew, 2003; Hwang, Lee, \& Kim, 2012; Lutomirska, 2009; Paeglitis \& Freimanis, 2016). The implications of such an assumption are unknown but are likely to be significant (Caprani, 2005). Micu, OBrien, \& Sevillano (2016) propose using image analysis as an efficient survey method for vehicle lengths and intervehicle gaps. They show that images can provide data such as vehicle length, an estimate of vehicle class and gaps between vehicles, which are key parameters for the traffic load on long-span bridges. Although images may provide much valuable traffic information, until now, there was no method of inferring vehicle weights from them.

This paper proposes an algorithm which uses only vehicle lengths for the estimation of extreme traffic load on long-span bridges. One year of WIM data recorded at a site in Tennessee in the United States is used in this study. The data contains vehicle characteristics such as total length and weight. Monte Carlo simulation, which reflects the statistical relationship between vehicle length and weight, is applied. It is shown that the weight of vehicles may be estimated from their lengths using this relationship. Thousands of virtual snapshots of congested traffic are generated for three bridge lengths $(500 \mathrm{~m}$, $1000 \mathrm{~m}$, and $2000 \mathrm{~m}$ ). Each snapshot is of congested traffic with a total length equal to the corresponding bridge length. The weights of the vehicles in each snapshot are inferred from their lengths using Monte Carlo simulation. The intensity of traffic load is obtained for each simulated snapshot and is compared to that obtained from the recorded weight data. This study investigates the extreme values of traffic load intensity based on vehicle lengths. The intensity of load is extrapolated for each bridge length to determine the 75-year return period level. The extreme values using both inferred and recorded weights are compared for the three bridge lengths. The outcomes illustrate that extreme traffic load on long-span bridges can be accurately estimated using length data alone.

\author{
Elena Alexandra \\ Micu, \\ Eugene John OBrien, \\ Abdollah \\ Malekjafarian, \\ Michael Quilligan \\ Estimation \\ of Extreme \\ Load Effects \\ on Long-Span \\ Bridges Using \\ Traffic Image Data
}




\section{WIM data}

One year of WIM data is used in this study, containing 5.8 million vehicle records from $1^{\text {st }}$ January to $31^{\text {st }}$ December 2008, on an interstate highway (I-40) in Tennessee State. The data is part of the Long-Term Pavement Performance (LTPP) programme of US Federal Highway Administrations (FHWAs) (Walker \& Cebon, 2012; Walker, Selezneva, \& Wolf, 2012). In this site, the WIM sensors were embedded in both the slow and fast lanes, in one direction only. As the most significant heavy traffic happens during working days, 10 public holidays and 104 weekend days are removed from the data.

\subsection{Cleaning rules for the data}

Sivakumar \& Sheikh Ibrahim (2007) demonstrate that WIM systems are inaccurate and may record many errors. Therefore, different criteria (Enright, 2010) are applied in this section to check the accuracy of the WIM data and filter out spurious records. Those vehicles that are identified as measurement errors based on the cleaning guidelines detailed in Table 1 are removed. After filtering, 3.7 million vehicles were left in the data set consisting of 2.4 million in the slow lane and 1.3 million in the fast lane. All of these vehicles are considered in this study, but only the results from the slow lane are shown in the following Figures.

Table 1. Filtering criteria to identify records with likely errors

\begin{tabular}{ll}
\hline & For cars \\
\hline Speed & $<60 \mathrm{~km} / \mathrm{h} ;>140 \mathrm{~km} / \mathrm{h}$ \\
Gross vehicle weight & $<0.5 \mathrm{t} ;>6 \mathrm{t}$ \\
1st axle spacing & $<1.83 \mathrm{~m}(6 \mathrm{feet}) ;>3.08 \mathrm{~m}(10.10 \mathrm{feet})$ \\
Total length & $<1$ st axle spacing \\
\hline & For trucks \\
\hline Speed & $<60 \mathrm{~km} / \mathrm{h} ;>120 \mathrm{~km} / \mathrm{h}$ \\
Gross vehicle weight & $<0.5 \mathrm{t} ;>100 \mathrm{t}$ \\
1st axle spacing & $<1.83 \mathrm{~m}(6 \mathrm{feet}) ;>13.72 \mathrm{~m}(45 \mathrm{feet})$ \\
Total length & $>36 \mathrm{~m}$ \\
Total length & $<1 \mathrm{st}$ axle spacing \\
\hline & General cleaning rules \\
\hline Total length & $<$ sum of axle spacing \\
The heaviest axle & $>40 \mathrm{t}$ \\
Gross vehicle weight & The difference between GVW \\
& and the sum of axle weights is more than 10\% \\
\hline
\end{tabular}




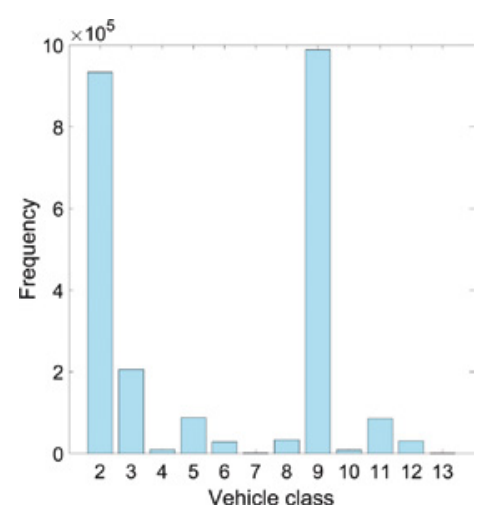

a) the frequency of vehicle classes

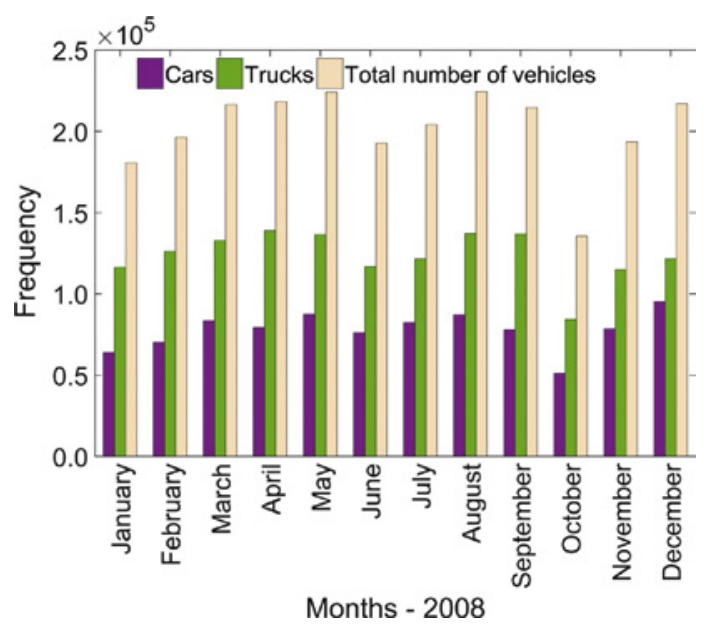

b) the frequency of vehicles by month of the year

Figure 1. Measured Weigh-in-Motion data after filtering

\subsection{Data investigation}

The data is classified according to the FHWA Traffic Monitoring Guide (FHWA, 1995). Class 2 is cars, and all other classes are referred to as "trucks" in the following discussion. Figure 1a shows the number of vehicles belonging to each class. It can be seen that Class 2 and Class 9 (5-axle truck) are the most common vehicle classes in the data by far. The very low number of cars relative to 5 -axle trucks is explained by the fact that this is the slow lane of a dual carriageway. Figure $1 \mathrm{~b}$ presents the number of cars, trucks and a total number of vehicles per month.

The hourly variation of cars and trucks by the time of day is illustrated for one day (23 ${ }^{\text {rd }}$ May) in Figure 2. The daytime traffic is much greater than at night time. The number of trucks overtakes the numbers of cars during the night. This is significant - it means that, while congestion is less likely at night, a congestion event is likely to feature a higher percentage of trucks.

\section{Length-weight correlation}

\subsection{Segmentation of lengths}

The frequencies of the vehicle with a specific length and GVWs are illustrated in Figure 3. Bivariate kernel density estimators (KDE) (Jones \& Kappenman, 1992) are used to estimate the probability density of each 


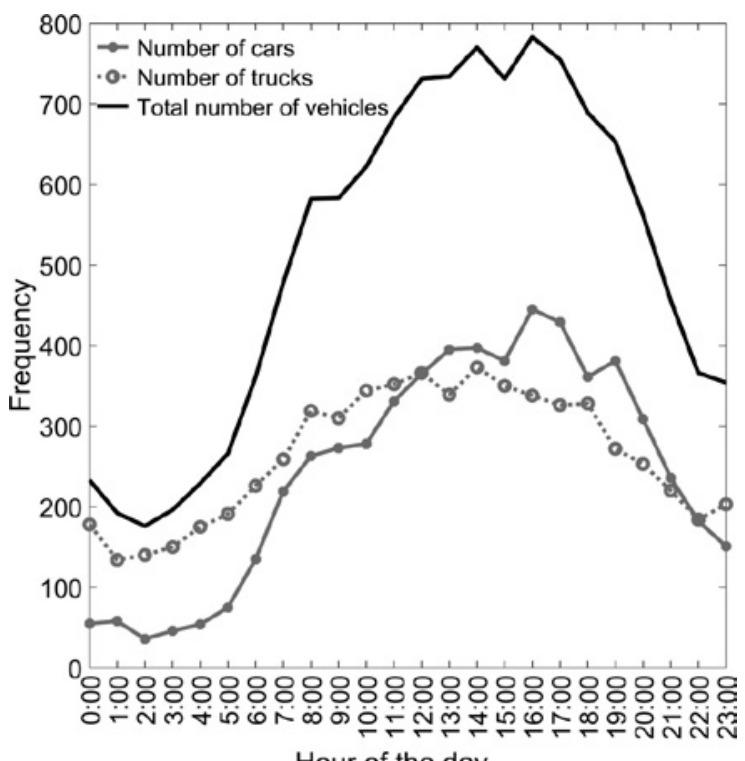

Hour of the day

Figure 2. The frequency of car and truck data by time of day

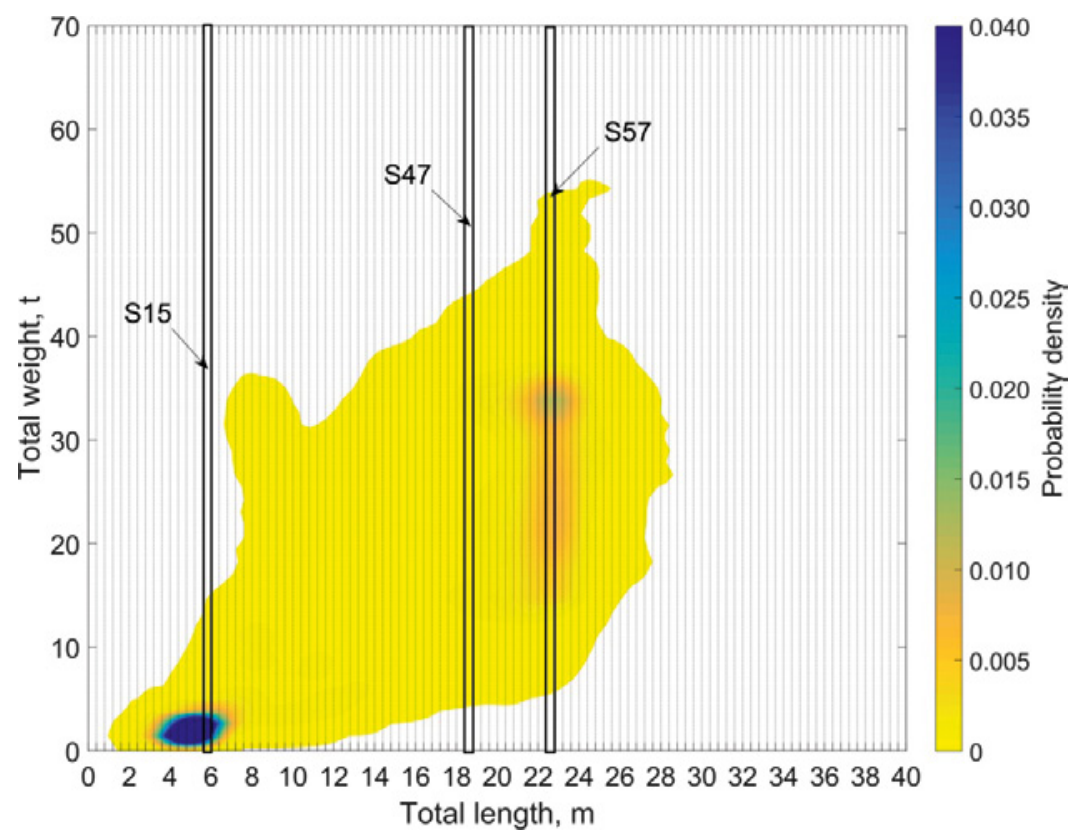

Note: white $=$ no data

Figure 3. Vehicle length-weight relationship 


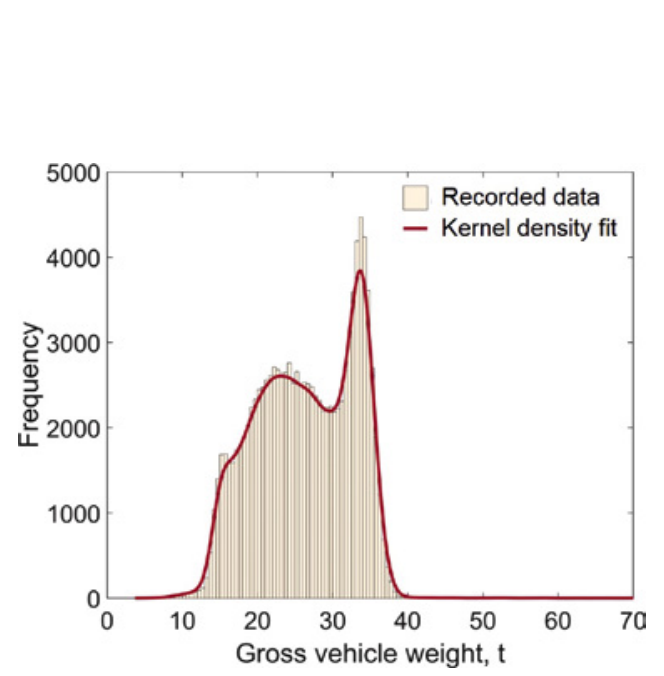

Figure 4. The distribution of gross weight for Segment S57

length and GVW pair. In Figure 3, the high density of cars and light vehicles is seen between $2.5 \mathrm{~m}$ and $7.0 \mathrm{~m}$ length, weighing from $0.5 \mathrm{t}$ to $5.0 \mathrm{t}$. The highest density pair for trucks is from 21.0-24.0 m length and $34 \mathrm{t}$ weight. The data has a low density between these two peaks. The contour plot confirms the dominance of cars and 5-axle trucks evident in Figure 1a.

The whole database is divided into 100 segments according to the total lengths. Each segment includes the vehicles with a length within a $0.4 \mathrm{~m}$ interval. For example, segment S15 includes vehicles with lengths in the range, $5.6 \mathrm{~m}$ to $6.0 \mathrm{~m}$. A cross section of Figure 3 is defined for each segment. For example, Figure 4 shows the histogram of the numbers for Segment S57 (length 22.4-22.8 m). Univariate KDEs are used in Figure 4 to approximate the probability density of the measured data.

Probability density functions (PDFs) are defined this way for each segment for the whole year of data and each month separately (Figure 5). Each graph contains 13 curves comparing the probability densities for vehicles in each month with the whole year. Figure 5a represents short vehicles $(5.6 \mathrm{~m}$ to $6.0 \mathrm{~m})$ and has a high probability density of light vehicles (around $2 \mathrm{t}$ ). It can be seen that there are some months where the PDF is significantly different from the yearly function. These may correspond to holiday seasons when normal patterns are disrupted. Figures $5 b$ and $5 c$ present the PDFs for longer and therefore heavier vehicles. The first peak of the black distribution (corresponding to the whole year) in Figure 5c corresponds to partially loaded trucks in segment S57, weighing around $20 \mathrm{t}$. The second peak gives the probability of fully loaded trucks, weighing around $34 \mathrm{t}$. According to the American Guide on Traffic Monitoring (FHWA, 1995; USDOT, 2000), for a vehicle up to $23 \mathrm{~m}$ long, the maximum GVW is $39.5 \mathrm{t}$ for a 5-axle truck and $43.5 \mathrm{t}$ to $46.5 \mathrm{t}$ for 6 axle truck, depending on tridem length. 


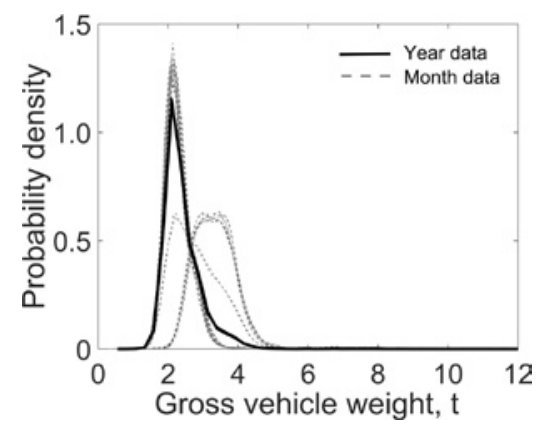

a) $\mathrm{S} 15=(5.6,6.0]$

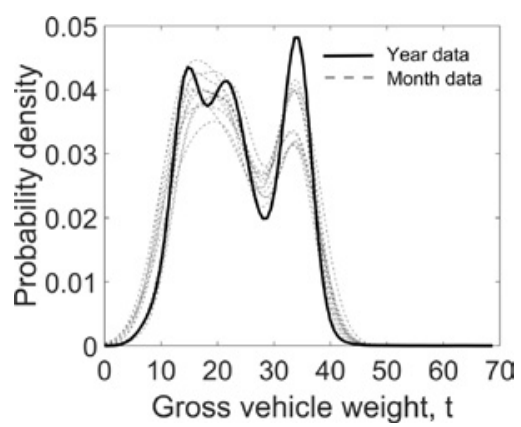

b) $S 47=(18.4,18.8]$

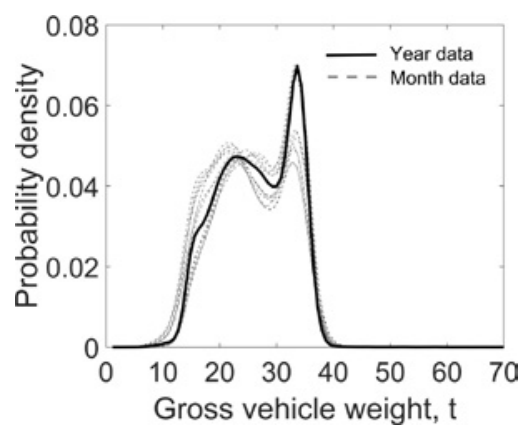

c) $\mathrm{S} 57=(22.4,22.8]$

Figure 5. Probability density functions for Weigh-in-Motion data

\subsection{Inferring weight from length}

In this paper, it is assumed that the total lengths of vehicles in congested traffic on a long span bridge will be available from a camera installed on the bridge. It is further assumed that WIM data, which is representative of the length/weight relationship, will be available. This could be from a WIM system on the approach to the bridge, for example, which collects accurate data during free-flowing conditions. The relationship between lengths and weights in the database is used to infer typical weights of vehicles from their lengths. For a given vehicle length (segment), the cumulative distribution function (CDF) (Xue \& Titterington, 2011) is constructed from the PDF of the data in that segment. Using Monte Carlo simulation, a random number is 
used to generate a weight consistent with the CDF. While this is highly inaccurate for individual vehicles, it gives simulated data consistent with the underlying statistical attributes of the data.

\section{Numerical validation}

\subsection{Benchmark and simulation}

Bridge load using vehicles of known weight is used in benchmarks to assess the accuracy of load calculations based on inferred weights. One thousand "snapshots" of congested traffic are generated for three bridges with different lengths $(500 \mathrm{~m}, 1000 \mathrm{~m}$ and $2000 \mathrm{~m})$. The vehicles in the snapshots are taken from the recorded WIM database using a random process. A working day within the database is randomly chosen, and a vehicle is selected randomly inside this working day data. This vehicle represents the starting point. The snapshot is filled with vehicles recorded in WIM data from that starting point until the length is fully covered. To remove uncertainty due to variable inter-vehicle gaps, these are all set to a constant value of $1.5 \mathrm{~m}$ (Buckland, Navin, Zidek, \& McBryde, 1980). The gaps are assumed to be bumper-to-bumper distances. The benchmark uses the known "true" weight and length information of all the vehicles. It is important to note that the sequence of vehicles within each snapshot is the same as the sequence of vehicles in the database. Figure 6 illustrates an example of a snapshot taken for a $500 \mathrm{~m}$ bridge. The vehicles and gaps are displayed as rectangles. The dark (red) rectangles represent the vehicles (cars or trucks), and the light (grey) rectangles represent the $1.5 \mathrm{~m}$ gaps. It is important to note that this does not represent an appropriate car/truck mix for congested conditions as it has been extracted from free-flowing WIM data.

One thousand snapshots are generated similarly, assuming that only vehicle length information is available for each vehicle. Weights are

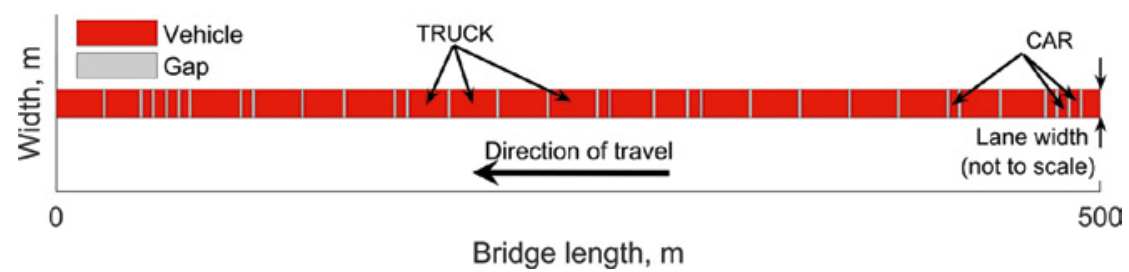

Figure 6. A snapshot sample 
inferred from the lengths using Monte Carlo simulation, as described above. The 1000 simulations are repeated three times for each bridge length to check the repeatability of the approach.

\subsection{Intensity of load}

Total traffic load is calculated, for both the benchmark and using the inferred weights for the three bridge lengths. Figure 7 gives the PDFs for the intensity of load (total weight per unit length) for each bridge length. It shows that the intensity of load for this site varies randomly in the range, $2.5 \mathrm{kN} / \mathrm{m}$ to $10.5 \mathrm{kN} / \mathrm{m}$. Figure $7 \mathrm{a}$ shows the PDFs for the actual weights for the three bridge lengths. As expected, there is less variability

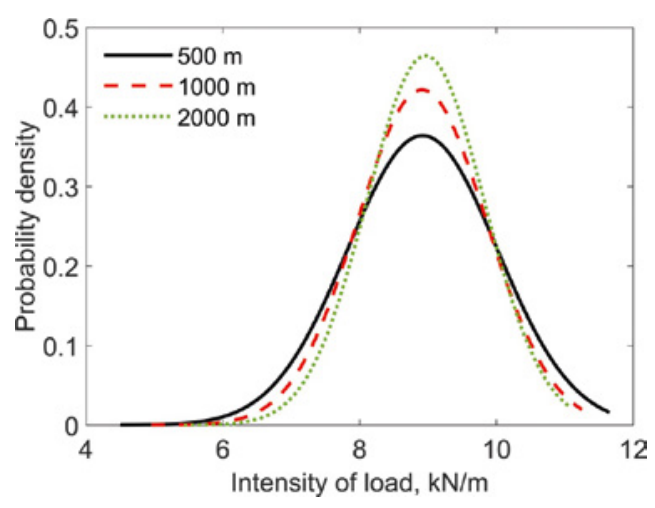

a) benchmark (recorded)

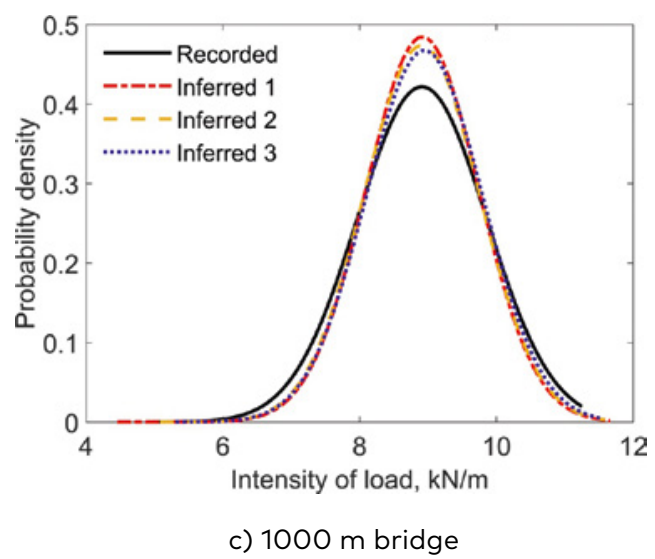

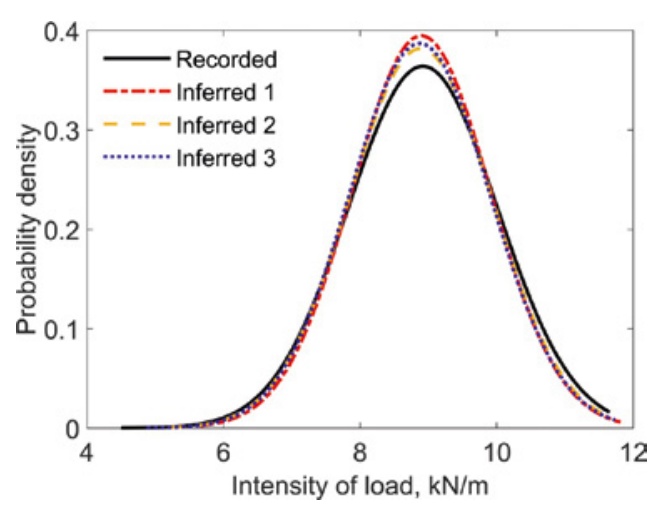

b) $500 \mathrm{~m}$ bridge

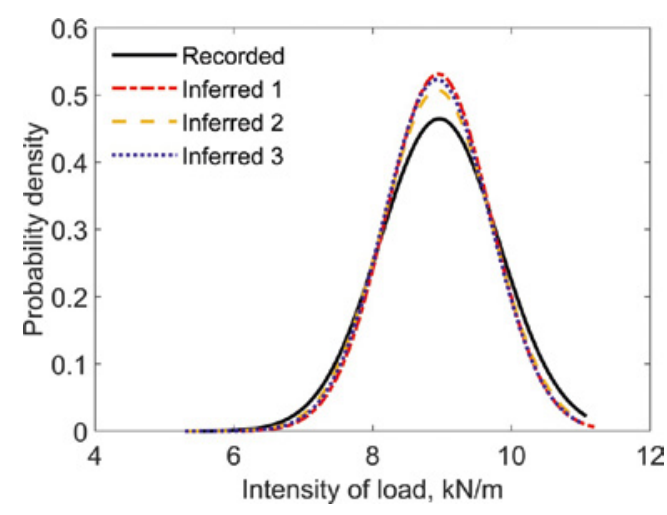

d) 2000 bridge

Figure 7. The probability distribution for the intensity of load 
of average load intensity in longer bridges (standard deviation reduces). Figures $7 \mathrm{~b}-7 \mathrm{~d}$ compare these PDFs of benchmark to the corresponding distributions using inferred weights for $500 \mathrm{~m}, 1000 \mathrm{~m}$ and $2000 \mathrm{~m}$ bridge lengths, respectively. The distributions using inferred weights match the benchmark distributions very well. However, the accuracy does appear to decrease with increasing bridge length.

\section{Extreme traffic loading events}

\subsection{Normal probability graphs}

Figure 8 is a Normal probability paper plot (Chambers, Cleveland, Kleiner, \& Tukey, 1983) for load intensity on the $500 \mathrm{~m}$ bridge. Each point represents the intensity of load for a snapshot and the associated probability. The trend in the data is substantially linear, demonstrating good consistency with a normal distribution (Benjamin \& Cornell, 1970; Nowak \& Collins, 2012). There is a good match between the best fit to the benchmark data (solid black line) and the best fit for the inferred weights data (red dashed line). It is seen that the points depart from the straightline fits in the upper tail for both distributions, as is typical of these kinds of plots (the upper tail contains approximately $4 \%$ of all points). As expected, the snapshots, which form the upper tails of the graph, involve large numbers of heavy vehicles.

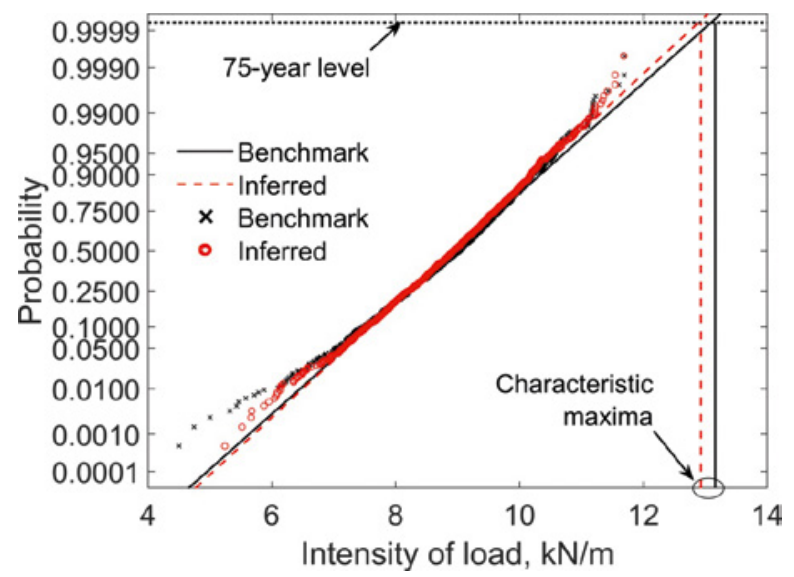

Figure 8. Normal probability paper plot of the benchmark and inferred distributions of load intensity for $500 \mathrm{~m}$ bridge length 


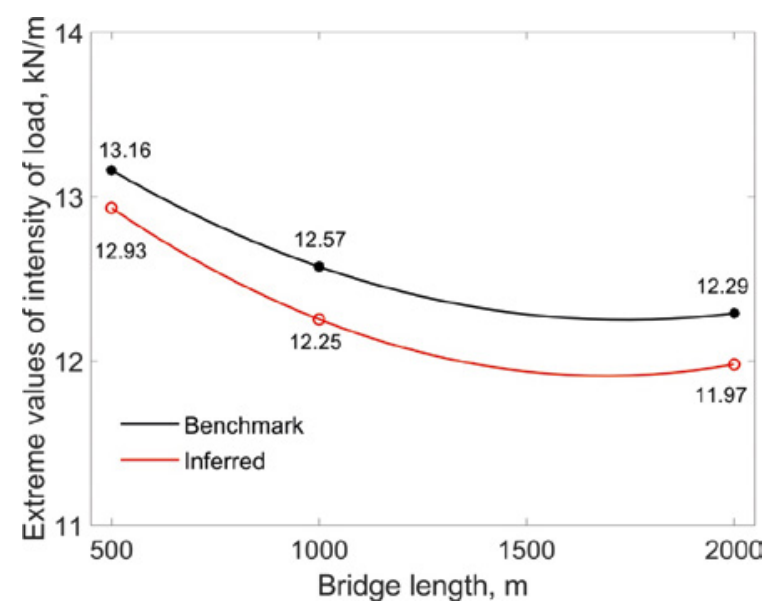

Figure 9. Extreme intensity of traffic load for the 75-year reference time

\subsection{Extreme values of traffic load}

The extreme value for intensity of load (Castillo, 1988; Jacob, 1991) is found for each bridge length for a 75-year return period (Cremona, 2001; Nowak \& Szerszen, 1998; OBrien \& Enright, 2011; OBrien, Enright, \& Getachew, 2010). Figure 8 illustrates this process for the $500 \mathrm{~m}$ bridge. This probability is, assuming one jam (snapshot) per day and 250 working days per year. The return period probability depends on how many jam-inducing loading events occur per year. The assumption here of one per working day is just one possible assumption.

The corresponding 75-year characteristic maximum load intensities for the three bridge lengths are calculated and illustrated in Figure 9 for the benchmark and inferred weight cases. The extreme values for the benchmark are matched well by the extreme values using inferred weights - there is less than $3 \%$ difference between the two cases. It is concluded that the proposed approach provides acceptable accuracy for estimating the extreme traffic load for long span bridges.

\subsection{Multiple lane traffic and lane changing}

The variation in inter-vehicle gaps, number of lanes and the ability of vehicles to change lanes, may influence the results. In this section, Beta-distributed values are considered for inter-vehicle gaps according to vehicles type (Bailey, 1996), instead of setting a constant value. Figure 10 shows the distribution of inter-vehicle gaps that vary according to the type of vehicle before and after the gap. 


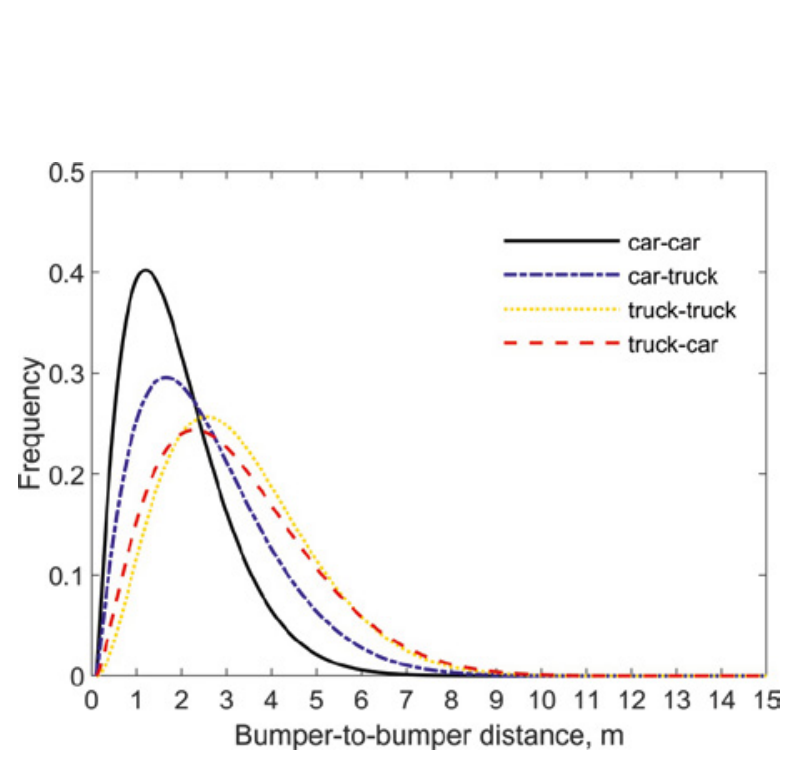

Figure 10. Beta distribution of bumper-to-bumper vehicle gaps (Bailey, 1996)

As there is generally more than one same-direction lane on longspan bridges, the study is also extended to two-lane cases. Since the vehicles might change lane as traffic becomes congested, a set of the lane, changing criteria, has been developed. This redistributes lane assignments from the free-flowing WIM dataset into traffic jam snapshots. As vehicles arrive at the jam location, queues build up. With more vehicles and a higher percentage of trucks, the queue in the slow lane tends to become longer than that in the fast lane, which results in a need for lane changes. The model assigns a probability of lane changing based on the difference of queue length between the lanes. A lower probability of lane changing is assigned to trucks based on studies by Ricketts \& Page (1997). This results in a greater number of truck platoons forming, which is significant for long-span bridge traffic load.

Three cases are considered in total, namely single-lane traffic, two-lane traffic without lane changing and two-lane traffic with lane changing. For each case, the inter-vehicle gaps are set to constant distances or Beta-distributed values. The snapshots are modelled using the procedure explained in Section 3. Table 2 presents the extreme values of load intensity using actual (recorded) vehicle weights and inferred weights for 75-year return periods.

In all cases, the extreme values calculated using the inferred weights closely follow the extreme values calculated using the actual weights of vehicles. It can be observed in the lane changing case that there is a more significant difference - around 5\% compared to around 3\% for the other cases. This difference may be because the process of inferring weights 
Table 2. Extreme values (75-year return period) for load intensity according to the number of lanes and gap assumptions

\begin{tabular}{|c|c|c|c|c|}
\hline \multirow{3}{*}{ Congestion } & \multirow{3}{*}{ Simulations } & \multicolumn{3}{|c|}{ Extreme values of intensity of load, kN/m } \\
\hline & & \multicolumn{3}{|c|}{ Bridge length } \\
\hline & & $500 \mathrm{~m}$ & $1000 \mathrm{~m}$ & $2000 \mathrm{~m}$ \\
\hline \multirow{3}{*}{$\begin{array}{l}\text { Single lane } \\
\text { (slow lane) } \\
\text { Constant gap }(1.5 \mathrm{~m})\end{array}$} & Benchmark & 13.16 & 12.57 & 12.29 \\
\hline & Inferred weights & 12.93 & 12.17 & 11.97 \\
\hline & $\%$ difference & 1.75 & 2.55 & 2.60 \\
\hline \multirow{3}{*}{$\begin{array}{l}\text { Single lane } \\
\text { (slow lane) } \\
\text { Random gaps }\end{array}$} & Benchmark & 12.19 & 11.77 & 11.37 \\
\hline & Inferred weights & 11.98 & 11.43 & 11.12 \\
\hline & $\%$ difference & 1.72 & 2.89 & 2.20 \\
\hline \multirow{3}{*}{$\begin{array}{l}\text { Two lanes } \\
\text { No lane changing } \\
\text { Constant gap }(1.5 \mathrm{~m})\end{array}$} & Benchmark & 21.09 & 20.55 & 19.83 \\
\hline & Inferred weights & 20.83 & 20.02 & 19.41 \\
\hline & $\%$ difference & 1.23 & 2.58 & 2.12 \\
\hline \multirow{3}{*}{$\begin{array}{l}\text { Two lanes } \\
\text { No lane changing } \\
\text { Random gaps }\end{array}$} & Benchmark & 19.26 & 18.83 & 18.23 \\
\hline & Inferred weights & 19.20 & 18.56 & 18.03 \\
\hline & $\%$ difference & 0.31 & 1.43 & 1.10 \\
\hline \multirow{3}{*}{$\begin{array}{l}\text { Two lanes } \\
\text { With lane changing } \\
\text { Constant gap }(1.5 \mathrm{~m})\end{array}$} & Benchmark & 22.83 & 22.48 & 22.13 \\
\hline & Inferred weights & 22.00 & 21.37 & 21.10 \\
\hline & $\%$ difference & 3.64 & 4.94 & 4.65 \\
\hline \multirow{3}{*}{$\begin{array}{l}\text { Two lanes } \\
\text { With lane changing } \\
\text { Random gaps }\end{array}$} & Benchmark & 21.18 & 20.68 & 20.37 \\
\hline & Inferred weights & 20.23 & 19.70 & 19.47 \\
\hline & $\%$ difference & 4.49 & 4.74 & 4.42 \\
\hline
\end{tabular}

from lengths is established separately for each lane using the data recorded in that lane. It follows that the weights of the vehicles, which change lane, may be inferred with less accuracy.

\section{Conclusions}

This paper proposes an approach for the estimation of extreme traffic load on long-span bridges based on vehicles lengths and a known statistical weight-to-length relationship. One year of recorded Weigh-inMotion data is used in this research. The possible errors in the Weighin-Motion data are reduced by applying a set of cleaning rules to the raw data. A bivariate statistical distribution describes the relationship between vehicles lengths and their weights. Kernel Density fitting and 
Monte Carlo simulation are used to infer weights from lengths. Several snapshots are extracted from the Weigh-in-Motion data to represent images of congested traffic for three bridge lengths. The vehicles weights in each snapshot are inferred using Monte Carlo simulation and the intensity of load calculated. The inferred distribution for the intensity of load is normally distributed and match well with the corresponding benchmark distribution. Extreme intensity of traffic load for a 75-year return period is calculated for the benchmark and using inferred weights for three bridge lengths. The inference approach is shown to estimate extreme traffic load on a long-span bridge accurately.

\section{REFERENCES}

Aghabayk, K., Sarvi, M., \& Young, W. (2012). Understanding the dynamics of heavy vehicle interactions in car-following. Journal of Transportation Engineering, 138(12), 1468-1475. https://doi.org/10.1061/(asce)te.1943-5436.0000463

Al-Kaisy, A. F., Hall, F. L., \& Reisman, E. S. (2002). Developing passenger car equivalents for heavy vehicles on freeways during queue discharge flow. Transportation Research Part A: Policy and Practice, 36(8), 725-742. https://doi.org/10.1016/S0965-8564(01)00032-5

Al-Kaisy, A., Jung, Y., \& Rakha, H. (2005). Developing passenger car equivalency factors for heavy vehicles during congestion. Journal of transportation engineering, 131(7), 514-523.

https://doi.org/10.1061/(ASCE)0733-947X(2005)131:7(514)

Attard, M. M., \& Stewart, M. G. (1998). A two parameter stress block for high-strength concrete. Structural Journal, 95(3), 305-317.

Bailey, S. (1996). Basic principles and load models for the structural safety evaluation of existing road bridges. Lausanne, Swiss Federal Institute of Technology, 1996 (Doctoral dissertation, thesis).

Benjamin, J. R., \& Cornell, C. A. (1970). Probability, Statistics, and Decision for Civil Engineers. New York, New York: McGraw-Hill".

Bruls, A., Croce, P., De Falena, S., \& Sedlacek, G. (1996). ENV1991-Part 3: Traffic loads on bridges. Calibration of road load models for road bridges. In Proceedings of IABSE Colloquium on Basis of Design and Actions on Structures (pp. 439-453).

Buckland, P. G. (1991). North American and British long-span bridge loads. Journal of Structural engineering, 117(10), 2972-2987. https://doi.org/10.1061/(ASCE)0733-9445(1991)117:10(2972)

Buckland, P. G., McBryde, J. P., Navin, F. P., \& Zidek, J. V. (1978). Traffic loading of long span bridges. Transportation Research Record, (665).

Buckland, P. G., Navin, F. P. D., Zidek, J. V., \& McBryde, J. P. (1980). Proposed vehicle loading of long-span bridges. Journal of the Structural Division, 106(ASCE 15306 Proceeding). 
Caprani, C. C. (2005). Probabilistic analysis of highway bridge traffic loading. Other resources, 1.

Caprani, C. C. (2010). Using microsimulation to estimate highway bridge traffic load. In Proc. 5th Intl. Conf. on Bridge Maintenance, Safety and Management.

Caprani, C. C. (2012). Calibration of a congestion load model for highway bridges using traffic microsimulation. Structural Engineering International, 22(3), 342-348. https://doi.org/10.2749/101686612x13363869853455

Caprani, C. C., \& OBrien, E. J. (2008). The governing form of traffic for highway bridge loading. In Proceedings of 4th Symposium on Bridge and Infrastructure Research in Ireland (pp. 53-60). National University of Ireland, Galway.

Caprani, C. C., OBrien, E. J., \& Lipari, A. (2016). Long-span bridge traffic loading based on multi-lane traffic micro-simulation. Engineering Structures, 115, 207-219. https://doi.org/10.1016/j.engstruct.2016.01.045

Carey, C., OBrien, E. J., Malekjafarian, A., Lydon, M., \& Taylor, S. (2017). Direct field measurement of the dynamic amplification in a bridge. Mechanical Systems and Signal Processing, 85, 601-609. https://doi.org/10.1016/j.ymssp.2016.08.044

Castillo, E. (1988). Extreme Value Theory in Engineering Academic Press. New York.

Chambers, J., Cleveland, W., Kleiner, B., \& Tukey, P. (1983). Graphical methods for data analysis. Belmont, CA: Wadsworth.

Cremona, C. (2001). Optimal extrapolation of traffic load effects. Structural Safety, 23(1), 31-46. https://doi.org/10.1016/S0167-4730(00)00024-2

Darmawan, M. S., \& Stewart, M. G. (2007). Spatial time-dependent reliability analysis of corroding pretensioned prestressed concrete bridge girders. Structural Safety, 29(1), 16-31. https://doi.org/10.1016/j.strusafe.2005.11.002

Ditlevsen, 0. (1994). Traffic loads on large bridges modeled as white-noise fields. Journal of engineering mechanics, 120(4), 681-694. https://doi.org/10.1061/(ASCE)0733-9399(1994)120:4(681)

Enright, B. (2010). Simulation of traffic loading on highway bridges.

Enright, B., Carey, C., \& Caprani, C. C. (2013). Microsimulation evaluation of Eurocode load model for American long-span bridges. Journal of Bridge Engineering, 18(12), 1252-1260.

https://doi.org/10.1061/(ASCE)BE.1943-5592.0000546

Ferrari, P. (1989). The effect of driver behaviour on motorway reliability. Transportation Research Part B: Methodological, 23(2), 139-150. https://doi.org/10.1016/0191-2615(89)90037-4

FHWA (1995). Traffic Monitoring Guide (3rd ed.). Washington, D.C.: U.S. Department of Transportation Federal Highway Administration Guide, T. M., \& DOT, U. (1995). FHWA-PL-95-031. Federal Highway Administration, Washington, $D C$.

Getachew, A. (2003). Traffic load effects on bridges, statistical analysis of collected and Monte Carlo simulated vehicle data (Doctoral dissertation, Byggvetenskap).

Hayrapetova, A. A., O'Connor, A. J., \& OBrien, E. J. (2012). Traffic Load Models for Long Span Bridges. 
Hwang, E. S., Lee, K. T., \& Kim, D. Y. (2012, September). Modelling of truck traffic for long span bridges. In IABSE Congress Report (Vol. 18, No. 14, pp. 1112-1119). International Association for Bridge and Structural Engineering.

Jacob, B. (1991). Methods for the Prediction of Extreme Vehicular Loads and Load Effects on Bridges Report of Subgroup 8, Eurocode 1. Traffic Loads on Bridges.

Jones, M. C., \& Kappenman, R. F. (1992). On a class of kernel density estimate bandwidth selectors. Scandinavian Journal of Statistics, 337-349.

Klein, L. A., Mills, M. K., \& Gibson, D. R. (2006). Traffic detector handbook: Third editionvolume ii. Federal Highway Administration, Turner-Fairbank Highway Research Center, FHWA-HRT-06-139.

Krauß, S. (1998). Microscopic modeling of traffic flow: Investigation of collision free vehicle dynamics (Doctoral dissertation, Universitat zu Koln.).

Lutomirska, M. (2009). Live load models for long span bridges. Civil Engineering Dissertations and Student Research, 1.

Micu, A., O’Brien, E. J., \& Sevillano, E. (2016, August). Application of Image Processing to the Analysis of Congested Traffic. In Civil Engineering Research in Ireland 2016, Galway, Ireland, 29-30 August, 2016. Civil Engineering Research Association of Ireland.

Moses, F. (1979). Weigh-in-motion system using instrumented bridges. Journal of Transportation Engineering, 105(3).

Nowak, A. S., \& Collins, K. R. (2012). Reliability of structures. CRC Press.

Nowak, A. S., Lutomirska, M., \& Sheikh Ibrahim, F. I. (2010). The development of live load for long span bridges. Bridge Structures, 6(1, 2), 73-79. https://doi.org/10.3233/BRS-2010-006

Nowak, A. S., \& Szerszen, M. M. (1998). Bridge load and resistance models. Engineering structures, 20(11), 985-990. https://doi.org/10.1016/S0141-0296(97)00193-4

OBrien, E. J., \& Enright, B. (2011). Modeling same-direction two-lane traffic for bridge loading. Structural safety, 33(4-5), 296-304. https://doi.org/10.1016/j.strusafe.2011.04.004

OBrien, E. J., Enright, B., \& Getachew, A. (2010). Importance of the tail in truck weight modeling for bridge assessment. Journal of Bridge Engineering, 15(2), 210-213. https://doi.org/10.1061/(ASCE)BE.1943-5592.0000043

OBrien, E. J., Hayrapetova, A., \& Walsh, C. (2012). The use of micro-simulation for congested traffic load modeling of medium-and long-span bridges. Structure and Infrastructure Engineering, 8(3), 269-276. https://doi.org/10.1080/15732471003640477

OBrien, E. J., Lipari, A., \& Caprani, C. C. (2015). Micro-simulation of single-lane traffic to identify critical loading conditions for long-span bridges. Engineering Structures, 94, 137-148. https://doi.org/10.1016/j.engstruct.2015.02.019

Paeglitis, A., \& Freimanis, A. (2016). Comparision of Constant-Span and Influence Line Methods for Long-Span Bridge Load Calculations. The Baltic Journal of Road and Bridge Engineering, 11(1), 84-91. https://doi.org/10.3846/bjrbe.2016.10 
Pines, D., \& Aktan, A. E. (2002). Status of structural health monitoring of longspan bridges in the United States. Progress in Structural Engineering and materials, 4(4), 372-380. https://doi.org/10.1002/pse.129

Ricketts, N. J., \& Page, J. (1997). Traffic data for highway bridge loading. TRL REPORT 251.

Sarvi, M. (2013). Heavy commercial vehicles-following behavior and interactions with different vehicle classes. Journal of advanced transportation, 47(6), 572-580. https://doi.org/10.1002/atr.182

Sedlacek, G., Merzenich, G., Paschen, M., Bruls, A., Sanpaolesi, L., Croce, P., ... \& Hanswille, G. (2008). Background document to EN 1991-Part 2-Traffic loads for road bridges-and consequences for the design. JRC scientific and technical reports.

Sivakumar, B., \& Sheikh Ibrahim, F. I. (2007). Enhancement of bridge live loads using weigh-in-motion data. Bridge Structures, 3(3, 4), 193-204. https://doi.org/10.1080/15732480701515386

Stewart, M. G. (2001). Reliability-based assessment of ageing bridges using risk ranking and life cycle cost decision analyses. Reliability Engineering \& System Safety, 74(3), 263-273. https://doi.org/10.1016/S0951-8320(01)00079-5

Stewart, M. G., \& Val, D. V. (1999). Role of load history in reliability-based decision analysis of aging bridges. Journal of structural engineering, 125(7), 776-783. https://doi.org/10.1061/(ASCE)0733-9445(1999)125:7(776)

Treiber, M., Hennecke, A., \& Helbing, D. (2000). Microscopic simulation of congested traffic. In Traffic and granular flow'99 (pp. 365-376). Springer, Berlin, Heidelberg. https://doi.org/10.1007/978-3-642-59751-0_36

USDOT (2000). Comprehensive truck size and weight study. FHWA Publication number FHWA-PL-00-029.

Walker, D., \& Cebon, D. (2012). The metamorphosis of LTPP traffic data. In 6th International Conference on Weigh-In-Motion (ICWIM 6) International Society for Weigh-In-MotionInstitut Francais des Sciences et Technologies des Transports, de l'Aménagement et des Réseaux (IFSTARR) International Transport ForumForum of European National Highway Research Laboratories (FEHRL) Transportation Research BoardFederal Highway Administration.

Walker, D., Selezneva, O., \& Wolf, D. J. (2012). Findings from LTPP SPS WIM systems validation study. In 6th International Conference on Weigh-In-Motion (ICWIM 6) International Society for Weigh-In-MotionInstitut Francais des Sciences et Technologies des Transports, de l'Aménagement et des Réseaux (IFSTARR) International Transport ForumForum of European National Highway Research Laboratories (FEHRL) Transportation Research BoardFederal Highway Administration.

Xue, J. H., \& Titterington, D. M. (2011). The p-folded cumulative distribution function and the mean absolute deviation from the p-quantile. Statistics \& Probability Letters, 81(8), 1179-1182. https://doi.org/10.1016/j.spl.2011.03.014

Yoo, H., \& Green, P. (1999). Driver behavior while following cars, trucks, and buses (Vol. Report No. UMTRI-99-14). The University of Michigan Transportation Research Institute. (http://www.umich.edu/ driving/ publications/UMTRI-99-14.pdf) 